\title{
Hoe groeien te vroeg geboren kinderen in Nederland gedurende de eerste vier levensjaren?
}

\section{Resultaten van het Pinkeltje Onderzoek II}

Het volgen van de groei is een essentieel onderdeel van de gezondheidszorg voor kinderen. In het bijzonder voor te vroeg geboren kinderen zijn er veel factoren die tot verstoring van de groei kunnen leiden. Het is aannemelijk dat groeiachterstand bij te vroeg geboren kinderen vaker voorkomt en dat hun groei anders verloopt dan bij op tijd geboren kinderen. Specifieke kennis hierover ontbreekt, zeker waar het matig te vroeg geboren kinderen betreft. Een van de hoofddoelstellingen van het Pinkeltje Onderzoek was dan ook te onderzoeken hoe de groei wat betreft gewicht, lengte en hoofdomtrek bij te vroeg geboren kinderen verloopt gedurende de eerste 4 levensjaren en of er bij de geboorte factoren zijn aan te wijzen die de kans op achterblijvende groei vergroten. Ten slotte was er de wens om groeidiagrammen voor te vroeg geboren kinderen te maken.

In dit artikel vatten we de resultaten samen van 2 internationaal gepubliceerde artikelen over de groei van te vroeg geboren kinderen in Nederland vanaf de geboorte tot 4 jaar. Deze studies laten zien dat groeiachterstand in zowel gewicht als lengte vaker voorkomt bij te vroeg geboren kinderen dan bij hun op tijd geboren leeftijdgenoten. Hun hoofdomtrek is op de leeftijd van 1 jaar vergelijkbaar met die van op tijd geboren leeftijdgenoten. Vooral een laag geboortegewicht voor de zwangerschapsduur en een kleine lengte van moeder ( $<-1 \mathrm{SD}$ ) voorspellen een groeiachterstand op de leeftijd van 4 jaar. Er zijn groeidiagrammen gemaakt voor jongens en meisjes van o-4 jaar gerelateerd aan het aantal weken zwangerschapsduur zoals we die kennen voor op tijd geboren kinderen. Ze bieden de mogelijkheid om de groei van te vroeg geboren kinderen nauwkeurig te volgen.

\section{Inleiding}

Vroeggeboorte komt veel voor (in Nederland wordt circa $8 \%$ van de kinderen te vroeg geboren) en het is duidelijk dat een vroeggeboorte aanzienlijke gevolgen kan hebben voor de gezondheid van het kind, waaronder de groei. ${ }^{1}$ Onze kennis over het verloop van 'normale' groei bij te vroeg geboren kinderen is beperkt en de onduidelijkheid hierover zorgt vaak voor onrust bij ouders, artsen en andere zorgverleners. Een minder goede groei in de kindertijd leidt vaak tot groeiachterstand op volwassen leeftijd en heeft dan diverse neurologische en metabole gevolgen. ${ }^{2-5}$

De groei van veel te vroeg geboren kinderen (zwangerschapsduur < 32 weken) is veelvuldig onderzocht. De resultaten wijzen consequent uit dat een groeiachterstand van meer dan 2 standaarddeviaties bij deze kinderen vaker voorkomt dan bij op tijd geboren kinderen(10-20\% versus $2 \%$ ). ${ }^{2-4}$ Daarnaast staan veel te vroeg geboren kinderen juist bekend om hun vermogen groei in te halen. Gegevens over groei bij matig te vroeg gebo- ren kinderen (zwangerschapsduur $32 \mathrm{t} / \mathrm{m} 35$ weken) zijn, ondanks dat het grotere aantallen kinderen betreft (in Nederland ongeveer 11.000 kinderen per jaar), schaars. Matig te vroeg geboren kinderen worden geboren in de periode van de zwangerschap waarin de groeisnelheid haar hoogste punt bereikt. ${ }^{4}$ Het is aannemelijk dat het mislopen van de piek in de intra-uteriene groei tot groeiachterstand leidt. Het gebrek aan kennis over groei bij matig te vroeg geboren kinderen betekent ook dat er weinig bekend is over de invloed van factoren die de groei mogelijk beïnvloeden. In de literatuur worden tal van mogelijke factoren genoemd bij zowel het kind als de moeder.

Voor het goed kunnen volgen van de groei van te vroeg geboren kinderen zijn betrouwbare groeidiagrammen onontbeerlijk. In de praktijk worden de groeigegevens ingevuld in de gebruikelijke groeidiagrammen, waarbij de kalenderleeftijd wordt gecorrigeerd voor de zwangerschapsduur. Deze werkwijze is gebaseerd op de (niet geteste) aanname dat het verloop van de groei van te

\footnotetext{
E.M.J. ten Vergert-Jordans, jeugdarts KNMG, GGD Friesland en Universitair Medisch Centrum Groningen, afdeling Gezondheidswetenschappen. I.F.A. Bocca-Tjeertes, promovendus, jeugdarts, Universitair Medisch Centrum Groningen, Beatrix Kinderziekenhuis en Icare jeugdgezondheidszorg. J.M. Kerstjens, kinderarts-neonatoloog, Universitair Medisch Centrum Groningen, Beatrix Kinderziekenhuis. S. van Buuren, hoogleraar methodologie en statsitiek, TNO kwaliteit van Leven, Leiden en Universiteit Utrecht, faculteit Sociale Wetenschappen. A.F. de Winter, epidemioloog, Universitair Medisch Centrum Groningen, afdeling Gezondheidswetenschappen. S.A. Reijneveld, hoogleraar sociale geneeskunde, sociaal-geneeskundige/epidemioloog, Universitair Medisch Centrum Groningen, afdeling Gezondheidswetenschappen. A.F. Bos, hoogleraar neonatologie, Universitair Medisch Centrum Groningen, Beatrix Kinderziekenhuis. Correspondentie: I.tenvergert@ggdfryslan.nl.
} 
vroeg geboren kinderen overeenkomt met die van op tijd geboren kinderen. Er is geen consensus over de periode waarin de correctie voor de zwangerschapsduur moet worden voortgezet. Andere beschikbare groeidiagrammen (o.a. die van de World Health Organization; WHO) zijn gebaseerd op cross-sectionele of intra-uteriene groeigegevens en geven daarmee slechts een grove benadering van de werkelijkheid. ${ }^{6,7}$ Zonder voor zwangerschapsduur aangepaste groeidiagrammen leidt 'fysiologische ondergroei' bij te vroeg geboren kinderen gemakkelijk tot onrust en onnodige behandeling en kan het ontstaan van overgewicht bij te vroeg geboren kinderen onopgemerkt blijven.

Het eerste doel van het onderzoek waarover we in dit artikel rapporteren was om longitudinale groei van gewicht, lengte en hoofdomtrek bij matig te vroeg geboren kinderen te beschrijven. We veronderstelden dat het percentage kinderen met groeiachterstand onder matig te vroeg geborenen groter zou zijn dan onder op tijd geboren kinderen. Ten tweede wilden we factoren achterhalen die kunnen helpen groeiachterstand op de leeftijd van 4 jaar te voorspellen. We veronderstelden dat factoren die groeiachterstand ten tijde van de geboorte voorspellen ook op de leeftijd van 4 jaar nog groeiachterstand zouden voorspellen. Ons laatste doel was het maken van groeidiagrammen voor te vroeg geboren jongens en meisjes naar zwangerschapsduur. Dit artikel vat de resultaten samen van twee Engelstalige artikelen die hierover recent zijn verschenen., 8

\section{Methode}

\section{Studieopzet}

Deze studies over groei waren onderdeel van het Pinkeltje Onderzoek. De studieopzet is reeds eerder beschreven, ook in dit tijdschrift. ${ }^{10}$ Het Pinkeltje-cohort bestaat uit een grote steekproef van te vroeg geboren kinderen $(<36$ weken zwangerschapsduur) en willekeurig geselecteerde, op tijd geboren kinderen (38-42 weken zwangerschapsduur) als controlegroep. Om de representativiteit vooral ten aanzien van de lengtegroei te waarborgen, zijn organisaties voor jeugdgezondheidszorg benaderd in de oostelijke helft (Noord, Midden en Zuid) van Nederland. Het Pinkeltje Onderzoek is goedgekeurd door de Medisch Ethische Toetsingscommissie van het Universitair Medisch Centrum Groningen. De ouders gaven schriftelijk toestemming voor het gebruik van de gegevens.

Dertien organisaties voor jeugdgezondheidszorg selecteerden uit alle kinderen geboren tussen 1 januari 2002 en 31 mei 2003 de kinderen die werden geboren bij een zwangerschapsduur van minder dan 36 weken en na iedere 2 te vroeg geborenen een op tijd geboren kind. Om voldoende veel te vroeg geboren kinderen op te kunnen nemen, zijn via 5 neonatale Intensive Care Unit's (NICU's) een extra aantal kinderen geïncludeerd die na een zwan- gerschapsduur van minder dan 32 weken werden geboren tussen januari 2003 en december 2003. Kinderen met congenitale afwijkingen en syndromen werden geëxcludeerd.

Tijdens het laatste consultatiebureaubezoek (contactmoment 3 jaar en 9 maanden) werden gegevens uit de consultatiebureaudossiers van deze kinderen verzameld en werd ouders gevraagd een algemene vragenlijst in te vullen. We verzamelden eveneens gegevens uit de medische dossiers van ziekenhuizen. Uiteindelijk hebben we van 1123 ouders van matig te vroeg geboren kinderen toestemming gekregen om de groeigegevens te gebruiken. 981 van hen (87\%) vulden ook de vragenlijst in. We verzamelden eveneens voldoende gegevens van 567 veel te vroeg geboren kinderen. De totale onderzoeksgroep bestond uit $1690(1123+567)$ te vroeg geboren kinderen en 634 op tijd geboren kinderen. Moeders die niet deelnamen waren vaker van niet-Nederlandse afkomst en hadden een iets lagere sociaal-economische status (gemeten naar opleidingsniveau) dan deelnemende moeders. Afgezien hiervan vonden we geen verschillen tussen deelnemers en niet-deelnemers.

\section{Metingen en procedures}

De zwangerschapsduur werd in meer dan $95 \%$ van de gevallen bepaald op grond van de laatste menstruatie en bevestigd met een vroege echo. Kinderen van wie de zwangerschapsduur onduidelijk bleef, werden geëxcludeerd. Zwangerschapsduur werd uitgedrukt in hele weken; zo werd een zwangerschapsduur van 32 weken plus 6 dagen bijvoorbeeld gecodeerd als 32 weken. Een laag geboortegewicht voor de duur van de zwangerschap werd gedefinieerd als een geboortegewicht onder de -2 SDS (standaarddeviatiescores) volgens de Kloostermancurven bij de betreffende zwangerschapsduur. ${ }^{2}$ Gegevens over gewicht, lengte en hoofdomtrek werden verkregen uit routinecontroles in het ziekenhuis (incl. NICU's) en op de consultatiebureaus, vanaf de geboorte. Gewicht, lengte en hoofdomtrek werden volgens de gebruikelijke gestandaardiseerde methoden verkregen. We verzamelden gegevens over gewicht, lengte en hoofdomtrek ten tijde van de geboorte, op de dag van het laagste gewicht, gedurende de eerste levensweek en op de leeftijd van 1 maand, 3 maanden ( \pm 1 week), 6 maanden ( \pm 2 weken), 12 maanden ( \pm 2 weken), 2 jaar ( \pm 1 maand), 3 jaar ( \pm 1 maand) en tussen 3,5 en 4 jaar. De hoofdomtrek werd gemeten tot de leeftijd van 12 maanden.

De lengte van de moeder werd gemeten bij het consultatiebureaubezoek of anders verkregen via de oudervragenlijst. Gegevens over etnische afkomst, roken tijdens de zwangerschap, het opleidingsniveau, inkomen, duur van eventuele borstvoeding, meerlingzwangerschap, en conceptie via IVF/ICSI werden via de oudervragenlijst verkregen, aangevuld met informatie uit de medische dossiers. 


\section{Statistische analyses}

Ten eerste bepaalden we de achtergrondgegevens van de onderzoekspopulatie.

Ten tweede beschreven we de normale groei gedurende de eerste 4 levensjaren. Gewicht (incl. geboortegewicht), lengte en hoofdomtrek werden hiertoe omgezet in SDS. Groeiachterstand na de geboorte werd gedefinieerd als > 2 SD onder de mediane groei voor de Nederlandse populatie (Vierde landelijke groeistudie). We verzamelden de (groei)gegevens van de controlegroep van op tijd geboren kinderen en vergeleken deze met de gegevens uit de Vierde landelijke groeistudie (de Vijfde landelijke groeistudie was nog niet gepubliceerd). We vonden beide groepen vergelijkbaar en besloten de Vierde landelijke groeistudie vanwege het groter aantal gegevens van op tijd geboren kinderen ter vergelijking te gebruiken. Ten derde onderzochten we de mogelijke voorspellers van groeiachterstand door middel van logistische regressieanalyse. Factoren die univariaat geassocieerd waren met groeiachterstand $\operatorname{bij} p<0,20$ en uit de literatuur bekende factoren die mogelijk verband houden met een minder goede groei werden vervolgens met behulp van multivariabele logistische regressieanalyse getoetst. Voor het kind waren dit: zwangerschapsduur, laag geboortegewicht voor de zwangerschapsduur ('small for gestational age'; SGA), geslacht, in-vitrofertilisatie (IVF)/ intracytoplasmatische sperma-injectie (ICSI), deel van meerling en borstvoeding gedurende de eerste 6 maanden. Factoren voor de moeder waren: lengte, leeftijd, etniciteit, opleidingsniveau, roken tijdens de zwanger- schap en gezinsinkomen..$^{5,11,12}$ De data van kinderen met 'een passend gewicht voor zwangerschapsduur' ('appropriate for gestational age'; AGA) werden afzonderlijk geanalyseerd om verschillen tussen kinderen met een 'passend' en een 'te laag' geboortegewicht voor de zwangerschapsduur op te sporen. Alle analyses werden uitgevoerd met SPSS 16 voor Windows.

Ten vierde maakten we groeidiagrammen voor te vroeg geboren kinderen met dezelfde analysemethoden als bij de Vierde landelijke groeistudie werden gebruikt. Een uitgebreide technische uitleg over het tot stand komen van de groeidiagrammen en de statistische onderbouwing staan in ons artikel dat is gepubliceerd in het Journal of Pediatrics. ${ }^{9}$

\section{Resultaten}

\section{Achtergrondgegevens}

In totaal verzamelden we gegevens over 38.553 metingen bij te vroeg geborenen, verdeeld over 10 meetmomenten (gemiddeld 9,9 meetmomenten per kind). De gemiddelde zwangerschapsduur was 34 weken precies $(S D=1,0)$ en het gemiddelde geboortegewicht $2230 \mathrm{~g}(\mathrm{SD}=468$ ). De onderzoeksgroep bestond uit veel meerlingen (30\%), vooral tweelingen ( $94 \%$ van de meerlingen). Van de eenlingen was 2,8\% te licht voor de zwangerschapsduur (SGA). Het betrof vooral autochtone moeders (> 90\%). Tabel 1 geeft gedetailleerde informatie over de achtergrondgegevens van moeders en kinderen.

Tabel 1 Achtergrondgegevens van moeders en kinderen.

\begin{tabular}{|c|c|c|c|}
\hline & jongens & meisjes & totaal \\
\hline$n$ & $637(57,0 \%)$ & $486(43,0 \%)$ & $1123(100 \%)$ \\
\hline 32 & $73(11,5 \%)$ & $58(11,9 \%)$ & $131(11,7 \%)$ \\
\hline 33 & $131(20,6 \%)$ & $98(20,2 \%)$ & $229(20,4 \%)$ \\
\hline 34 & $173(27,2 \%)$ & $135(27,8 \%)$ & $308(27,4 \%)$ \\
\hline 35 & $260(40,8 \%)$ & $195(40,1 \%)$ & $455(40,5 \%)$ \\
\hline \multicolumn{4}{|c|}{ lengte van moeder } \\
\hline$<-2 S D$ & $38(6,0 \%)$ & $35(7,2 \%)$ & $73(6,5 \%)$ \\
\hline$-2 S D--1 S D$ & $109(17,1 \%)$ & $88(18,1 \%)$ & $197(17,5 \%)$ \\
\hline$-1 S D-+1 S D$ & $376(59,0 \%)$ & $278(57,2 \%)$ & $654(58,2 \%)$ \\
\hline $1 S D-2 S D$ & $56(8,8 \%)$ & $36(7,4 \%)$ & $92(8,2 \%)$ \\
\hline$>2 \mathrm{SD}$ & $11(1,7 \%)$ & $5(1,0 \%)$ & $16(1,4 \%)$ \\
\hline onbekend & $47(7,4 \%)$ & $44(9,1 \%)$ & $91(8,1 \%)$ \\
\hline \multicolumn{4}{|c|}{ roken tijdens de zwangerschap } \\
\hline niet & $483(75,8 \%)$ & $378(77,8 \%)$ & $861(76,7 \%)$ \\
\hline $1-5$ & $64(10,0 \%)$ & $38(7,8 \%)$ & $102(9,1 \%)$ \\
\hline $6-10$ & $44(6,9 \%)$ & $29(6,0 \%)$ & $73(6,5 \%)$ \\
\hline$>10$ & 31 (4,9\%) & $31(6,4 \%)$ & $62(5,5 \%)$ \\
\hline \multicolumn{4}{|l|}{ etniciteit } \\
\hline Nederlands & $580(91,1 \%)$ & $453(93,2 \%)$ & 1033 (92\%) \\
\hline
\end{tabular}




\begin{tabular}{|c|c|c|c|}
\hline & jongens & meisjes & totaal \\
\hline Nederlandse Antillen /Aruba & $2(0,3 \%)$ & $1(0,2 \%)$ & $3(0,3 \%)$ \\
\hline Surinaams & $5(0,8 \%)$ & $5(1,0 \%)$ & $10(0,9 \%)$ \\
\hline Turks & $4(0,6 \%)$ & $1(0,2 \%)$ & $5(0,4 \%)$ \\
\hline Marokkaans & $9(1,4 \%)$ & $3(0,6 \%)$ & $12(1,1 \%)$ \\
\hline Aziatisch & $8(1,3 \%)$ & $6(1,2 \%)$ & $14(1,2 \%)$ \\
\hline Afrikaans & $6(0,9 \%)$ & $4(0,8 \%)$ & $10(0,9 \%)$ \\
\hline anders & $23(3,6 \%)$ & $13(2,7 \%)$ & $36(3,2 \%)$ \\
\hline \multicolumn{4}{|l|}{ leeftijd moeder } \\
\hline$<20$ & $10(1,6 \%)$ & $5(1,0 \%)$ & $15(1,3 \%)$ \\
\hline $20-35$ & $565(88,7 \%)$ & $428(88,1 \%)$ & $993(88,4 \%)$ \\
\hline$>35$ & $61(9,6 \%)$ & $50(10,3 \%)$ & $111(9,9 \%)$ \\
\hline \multicolumn{4}{|l|}{ gezinsinkomen } \\
\hline$<1150$ euro & $51(8,0 \%)$ & $28(5,8 \%)$ & $79(7,0 \%)$ \\
\hline$>1150$ euro & $578(90,7 \%)$ & $448(92,2 \%)$ & $1026(91,4 \%)$ \\
\hline \multicolumn{4}{|l|}{ onderwijsniveau moeder } \\
\hline basisonderwijs & $203(31,9 \%)$ & $147(30,2 \%)$ & $350(31,2 \%)$ \\
\hline middelbaar/hoger onderwijs & $425(66,7 \%)$ & $329(67,7 \%)$ & $754(67,1 \%)$ \\
\hline \multicolumn{4}{|l|}{ IVF/ICSI } \\
\hline nee & $588(92,3 \%)$ & $437(89,9 \%)$ & $1025(91,3 \%)$ \\
\hline ja & $42(6,6 \%)$ & $44(9,1 \%)$ & $86(7,7 \%)$ \\
\hline geboortegewicht mediaan (SD) & $2291(475)$ & $2172(448)$ & $2240(468)$ \\
\hline \multicolumn{4}{|l|}{$\mathrm{SGA}(<\mathrm{P} 2)$} \\
\hline nee & $614(96,4 \%)$ & $479(98,6 \%)$ & $1093(97,3 \%)$ \\
\hline ja & $23(3,6 \%)$ & $7(1,4 \%)$ & $30(2,7 \%)$ \\
\hline \multicolumn{4}{|l|}{ meerling* } \\
\hline nee & $461(72,4 \%)$ & $330(67,9 \%)$ & $791(70,4 \%)$ \\
\hline ja & $176(27,7 \%)$ & $156(32,1 \%)$ & $332(29,6 \%)$ \\
\hline \multicolumn{4}{|l|}{ borstvoeding (eerste 6 maand) } \\
\hline nee & $545(85,7 \%)$ & $426(87,7 \%)$ & $971(86,5 \%)$ \\
\hline ja & $85(13,4 \%$ & $53(10,9 \%)$ & $138(12,3 \%)$ \\
\hline
\end{tabular}

* De groep meerlingen bestond voornamelijk uit tweelingen (94,0\%), de overigen waren drie- en vierlingen $(6,0 \%)$.

Normale groei van te vroeg geboren kinderen Na de geboorte op een gemiddelde leeftijd van 5,3 dagen lieten de matig te vroeg geboren kinderen een gemiddelde afname van $8,0 \%$ van het geboortegewicht zien. Daarna nam hun gewicht toe binnen een smalle marge tot de leeftijd van 6 maanden. Vanaf die leeftijd werd de variatie in groei groter, om weer te stabiliseren tussen het tweede en vierde jaar. Dit patroon was gelijk voor jongens en meisjes, hoewel de gemiddelden voor meisjes lager waren dan die voor jongens. Gewicht en lengte op de leeftijd van 1, 2 en 3 jaar worden weergegeven in tabel 2. Op de leeftijd van 4 jaar wogen matig te vroeg geboren jongens $16,9 \pm 2,3 \mathrm{~kg}$ (gemiddelde $\pm \mathrm{SD}$ ) en matig te vroeg geboren meisjes wogen $16, \mathrm{o} \mathrm{kg} \pm 2,4 \mathrm{~kg}$. Vergeleken met op tijd geboren jongens $(17,2 \pm 2,1 \mathrm{~kg})$ waren de te vroeg geboren jongens iets lichter $(p=0,09)$. Vergeleken met op tijd geboren meisjes $(16,7 \pm 2,07 \mathrm{~kg})$ waren te vroeg geboren meisjes lichter $(p<0,01)$.

De toename in lengte liet een vergelijkbare verdeling zien voor jongens en meisjes en die variatie bleef stabiel over de hele periode. Absolute lengtegroei was evenals bij gewicht, minder bij meisjes (tabel 2). Op de leeftijd van 4 jaar was de gemiddelde lengte $104 \pm 4,3 \mathrm{~cm}$ voor jongens en $103 \pm 4,1 \mathrm{~cm}$ voor meisjes. Ze waren daarmee wat korter $(p<0,01)$ dan de op tijd geboren groep uit de Vierde landelijke groeistudie.

Toename van de hoofdomtrek was eveneens gelijk voor jongens en meisjes. Opnieuw waren de gemiddelden voor meisjes lager dan die van jongens. De hoofdomtrek nam na een eerste periode van groeivertraging snel toe, en resulteerde uiteindelijk op de leeftijd van 1 jaar in een hoofdomtrek die vergelijkbaar was met die van de referentiegroep.

Uiteindelijk resulteerde de groei van matig te vroeg geboren kinderen op de leeftijd van 4 jaar tot een groeiachterstand ( $>2$ SD onder de mediane groei) in vooral gewicht en lengte (tabel 3 ). 48 kinderen $(4,4 \%$ ) hadden ondergewicht. Bij 50 kinderen $(4,6 \%)$ was sprake van een 
achterstand in lengtegroei. Groeiachterstand voor de hoofdomtrek kwam voor bij 10 matig te vroeg geboren kinderen $(1,2 \%)$. De groep kinderen met een groeiachterstand (gewicht en lengte) bestond vooral uit AGA-kinderen en daarnaast uit SGA-kinderen die onvoldoende inhaalgroei vertoonden.

\section{Voorspellers van groeiachterstand}

We vonden verschillende factoren die bij de geboorte groeiachterstand voorspelden (tabel 4). In het bijzonder voorspelden 'SGA' en 'lengte van de moeder onder de $-1 \mathrm{SD}$ (dat wil zeggen: $<1,65 \mathrm{~m}$ )' groeiachterstand in gewicht en lengte. Ook 'leeftijd van moeder > 35 jaar' en een 'Surinaams/Antilliaanse achtergrond' deden het risico op groeiachterstand voor het kind toenemen. Van alle socio-economische factoren vonden we dat alleen het 'opleidingsniveau van moeder' een relatie had met groeiachterstand van de hoofdomtrek.

In de multivariate analyses bleven als onafhankelijke voorspellers voor groeiachterstand in gewicht en lengte de 'SGA' en de 'lengte van moeder onder de -1 SD' overeind en het 'opleidingsniveau van moeder' voor groeiachterstand van de hoofdomtrek (tabel 5).

Tabel 2 Mediaan (gewicht en lengte) en aantal kinderen op of onder de -2 standaarddeviaties (SD) op de leeftijd 1, 2 en 3 jaar.

\begin{tabular}{l|l|l|l|l}
\hline $\begin{array}{l}\text { leeftijd } \\
\text { (jaren) }\end{array}$ & $\begin{array}{l}\text { mediane gewicht } \\
\left(P_{50}\right)(\mathrm{kg})\end{array}$ & $\begin{array}{l}\text { mediane lengte } \\
\left(P_{50}\right)(\mathrm{cm})\end{array}$ & $\begin{array}{l}\text { gewicht }<-2 S D \\
n(\%)\end{array}$ & $\begin{array}{l}\text { lengte<-2 SD } \\
n(\%)\end{array}$ \\
\hline jongens & & & $22(3,5)$ & $20(3,1)$ \\
1 & 9,9 & 75,5 & $20(3,1)$ & $20(3,1)$ \\
2 & 12,6 & 87,7 & $20(3,1)$ & $25(3,9)$ \\
3 & 15,1 & 97,5 & & $20(4,1)$ \\
meisjes & & & $29(6,0)$ & $18(3,7)$ \\
1 & 9,0 & 73,4 & $25(5,1)$ & $13(2,7)$ \\
2 & 11,8 & 86,2 & $23(4,7)$ & \\
3 & 14,3 & 96,4 & & \\
\hline
\end{tabular}

Tabel 3 Groeiachterstand in gewicht en lengte op de leeftijd van 4 jaar, met onderverdeling in kinderen met een te laag gewicht voor de zwangerschapsduur (SGA) en kinderen met een passend gewicht voor de zwangerschapsduur (AGA).

\begin{tabular}{|c|c|c|c|c|c|c|c|c|}
\hline & $\begin{array}{l}\text { gewicht }>-2 S D \\
\text { (\%) }\end{array}$ & p-waarde & $\begin{array}{l}\text { SGA } \\
n\end{array}$ & $\begin{array}{l}A G A \\
n\end{array}$ & $\begin{array}{l}\text { lengte }>-2 S D \\
n(\%)\end{array}$ & p-waarde & $\begin{array}{l}S G A \\
n\end{array}$ & $\begin{array}{l}A G A \\
n\end{array}$ \\
\hline totaal & $48(4,4)$ & 0,04 & 7 & 41 & $50(4,6)$ & 0,02 & 8 & 42 \\
\hline jongens & $21(3,4)$ & 0,52 & & & $32(5,6)$ & 0,05 & & \\
\hline meisjes & $27(5,8)$ & 0,02 & & & $18(3,8)$ & 0,35 & & \\
\hline
\end{tabular}

Tabel 4 Resultaten van de univariante logistische regressieanalyse voor laag gewicht (<-2SD), kleine lengte $(<-2 S D)$ en kleine hoofdomtrek $(\mathrm{HO})(<-2 \mathrm{SD})$, ruwe odds ratio's (OR), 95\%-betrouwbaarheidsintervallen (BI) en p-waarden.

\begin{tabular}{|c|c|c|c|}
\hline & $\begin{array}{l}\text { gewicht } 4 j<-2 S D \\
\text { OR }(95 \%-B I)\end{array}$ & $\begin{array}{l}\text { lengte } 4 j<-2 S D \\
\text { OR }(95 \%-B I)\end{array}$ & $\begin{array}{l}\text { hoofdomtrek } 1 j<-2 \text { SD } \\
\text { OR }(95 \%-B I)\end{array}$ \\
\hline \multicolumn{4}{|l|}{ zwangerschapsduur } \\
\hline 35 weken & 1 & 1 & 1 \\
\hline 32 en 33 weken & $1,2(0,6-2,4)$ & $1,1(0,6-2,1)$ & $1,0(0,3-1,9)$ \\
\hline 34 weken & $0,7(0,3-1.5)$ & $1,0(0,5-2,0)$ & $0,3(0,04-2,7)$ \\
\hline geslacht (meisjes vs. jongens) & $0,6(0,3-1,0)$ & $1,4(0,8-2,5)$ & $3,0(0,6-14,3)$ \\
\hline \multicolumn{4}{|l|}{ etniciteit } \\
\hline Nederlands & 1 & 1 & 1 \\
\hline Antillen/Aruba & $7,3(1,9-27,4)^{* *}$ & $6,7(1,7-25,3)^{* *}$ & $10,3(1,2-9,1)^{*}$ \\
\hline Turks/Marokkaans & $1,7(0,2-13,5)$ & $1,6(0,2-12,4)$ & $9,3(1,1-8,1)^{*}$ \\
\hline anders & $1,9(0,7-5,6)$ & $1,3(0,4-4,3)$ & - \\
\hline
\end{tabular}




\begin{tabular}{|c|c|c|c|}
\hline & $\begin{array}{l}\text { gewicht } 4 j<-2 S D \\
\text { OR }(95 \%-B I)\end{array}$ & $\begin{array}{l}\text { lengte } 4 j<-2 S D \\
\text { OR }(95 \%-B I)\end{array}$ & $\begin{array}{l}\text { hoofdomtrek } 1 j<-2 \text { SD } \\
\text { OR (95\%-BI) }\end{array}$ \\
\hline \multicolumn{4}{|l|}{ leeftijd moeder } \\
\hline 20-35 jaar & 1 & 1 & 1 \\
\hline$<20$ jaar & $1,6(0,2-12,6)$ & $1,8(0,2-14,0)$ & - \\
\hline$>35$ jaar & $0,6(0,2-2,0)$ & $2,2(1,0-4,6)^{*}$ & $2,2(0,5-10,4)$ \\
\hline \multicolumn{4}{|l|}{ lengte moeder } \\
\hline$-1 S D-+1 S D$ & 1 & 1 & 1 \\
\hline$<-2 S D$ & $3,4(1,5-4,1)^{* *}$ & $8,5(3,8-18,9)^{* *}$ & - \\
\hline$>-2 S D<-1 S D$ & $2,6(1,3-5,2)^{* *}$ & $5,1(2,6-10,2)^{* *}$ & $12,3(2,5-60,0)^{*}$ \\
\hline$>1 S D-<2 S D$ & $0,7(0,2-3,0)$ & - & - \\
\hline$>2 \mathrm{SD}$ & - & - & - \\
\hline laag opleidingsniveau moeder & $1,0(0,5-1,9)$ & $1,6(0,9-2,9)$ & $5,3(1,4-20,6)^{*}$ \\
\hline laag gezinsinkomen & $0,9(0,3-3,0)$ & $1,5(0,6-3,9)$ & - \\
\hline \multicolumn{4}{|l|}{ rokende moeder } \\
\hline niet & 1 & 1 & 1 \\
\hline 1-5 sigaretten/dag & $1,4(0,5-3,6)$ & $0,9(0,3-2,7)$ & $1,3(0,2-10,4)$ \\
\hline 6-10 sigaretten/dag & $1,9(0,7-5,1)$ & $0,6(0,2-2,7)$ & $1,8(0,2-14,6)$ \\
\hline > 10 sigaretten/dag & $1,8(0,6-5,2)$ & $1,5(0,5-4,4)$ & $2,1(0,3-17,4)$ \\
\hline IVF/ICSI (nee vs. ja) & $1,4(0,6-3,7)$ & $0,8(0,2-2,6)$ & $1,2(0,2-9,9)$ \\
\hline SGA (ja vs. nee) & $9,3(3,9-22,1)^{* *}$ & $7,2(2,9-17,7)^{* *}$ & - \\
\hline meerling (nee vs. ja) & $1,9(0,9-3,2)$ & $1,2(0,7-2,2)$ & $2,6(0,7-9,0)$ \\
\hline borstvoeding (ja vs. nee) & $0,7(03-1,5)$ & $0,5(0,3-1,1)$ & $1,2(0,2-9,8)$ \\
\hline
\end{tabular}

${ }^{*} \mathrm{p}<0,05$; $^{* *} \mathrm{p}<0,01$.

Tabel 5 Factoren die geassocieerd zijn met slechte groei op de leeftijd van 4 jaar (lengte en gewicht) en op de leeftijd van 1 jaar (hoofdomtrek). Ruwe en gecorrigeerde (\#) odds ratios (OR), 95\%-betrouwbaarheidsintervallen (BI) en p-waarden.

\begin{tabular}{|c|c|c|c|}
\hline & $\begin{array}{l}\text { gewicht } 4 j<-2 S D \\
\text { OR (95\% BI) }\end{array}$ & $\begin{array}{l}\text { lengte } 4 j<-2 S D \\
\text { OR }(95 \% \text { BI) }\end{array}$ & $\begin{array}{l}H O 1 j<-2 S D \\
\text { OR }(95 \% \text { BI) }\end{array}$ \\
\hline SGA, niet gecorrigeerd & $9,3(3,9-22,1)^{* *}$ & $7,2(2,9-17,7)^{* *}$ & \\
\hline SGA, gecorrigeerd & $9,5(3,9-23,1)^{* *}$ & $7,7(2,9-20,4)^{* *}$ & \\
\hline \multicolumn{4}{|l|}{ lengte moeder, niet gecorrigeerd } \\
\hline-1 SD of groter & 1 & 1 & \\
\hline-2 SD of groter maar $<-1$ SD & $2,6(1,3-5,2)^{* *}$ & $5,1(2,6-10,2)^{* *}$ & \\
\hline-2 SD of kleiner & $3,4(1,5-4,1)^{* *}$ & $8,5(3,8-18,9)^{* *}$ & \\
\hline \multicolumn{4}{|l|}{ lengte moeder, gecorrigeerd } \\
\hline-1 SD of groter & 1 & 1 & \\
\hline$-2 S D<-1 S D$ & $2,6(1,3-5,3)^{* *}$ & $4,9(2,4-9,9)^{* *}$ & \\
\hline$-2 \mathrm{SD}$ of kleiner & $2,8(1,1-7,4)^{*}$ & $7,0(2,9-16,5)^{* *}$ & \\
\hline \multicolumn{4}{|l|}{ opleidingsniveau moeder } \\
\hline niet gecorrigeerd (laag vs. hoger) & & & $5,3(1,4-20,6)^{* *}$ \\
\hline gecorrigeerd (laag vs. hoger) & & & $5,3(1,4-20,8)^{* *}$ \\
\hline
\end{tabular}

\# Gecorrigeerd voor zwangerschapsduur, etniciteit, opleidingsniveau moeder (laag vs. gemiddeld/hoog), gezinsinkomen (laag vs. gemiddeld/ hoog), roken tijdens de zwangerschap (integraal), leeftijd van moeder (integraal), IVF/ICSI (nee vs. ja), geslacht, meerlingstatus ( tweeling vs. drie/vierling) en borstvoeding tijdens de eerste 6 maanden (nee vs. ja).

${ }^{*} \mathrm{p}<0,05$; $^{* *} \mathrm{p}<0,01$. 


\section{Groeidiagrammen}

Om groeidiagrammen te kunnen maken, ontwikkelden we voor zowel gewicht als lengte en hoofdomtrek modellen naar zwangerschapsduur per week en geslacht. In de hele (kalender)leeftijdsrange die we bestudeerden (in dit geval 4 jaar) waren de mediane gewichten ( $\mathrm{P}_{50}$ ) lager bij de te vroeg geboren kinderen in alle zwangerschapstermijnen. De gewichtstoename nam af bij een kortere zwangerschapsduur. Dit patroon gold voor zowel jongens als meisjes. De variabiliteit was groter bij jongens dan bij meisjes, vooral bij een kortere zwangerschapsduur.

De mediane lengte $\left(\mathrm{P}_{5} \mathrm{O}\right)$ voor te vroeg geboren kinderen was in alle zwangerschapstermijnen kleiner gedurende de hele onderzoeksperiode (o-4 jaar): bij een kortere zwangerschapsduur daalde de lengtegroei. Er was geen verschil in groeipatroon bij jongens en meisjes, hoewel de variabiliteit bij jongens iets groter was, vooral bij een kortere zwangerschapsduur.

De mediane groei van de hoofdomtrek ( $\left.\mathrm{P}_{50}\right)$ was de eerste maanden na vroeggeboorte minder, maar daarna vergelijkbaar met die van op tijd geboren kinderen. Dit was voor beide geslachten het geval. Variabiliteit was opnieuw groter bij jongens dan bij meisjes, vooral bij kortere zwangerschapsduur.

Uiteindelijk zijn er 24 groeidiagrammen (voor zwangerschapsduur van $25 \mathrm{t} / \mathrm{m} 36$ weken, voor jongens en meisjes) gemaakt. Figuur 1 is een voorbeeld van zo'n groeidiagram.

Alle diagrammen zijn beschikbaar op de TNO-website (www.tno.nl/groei). De achterliggende gegevens worden via TNO gratis ter beschikking gesteld ten behoeve van inbouw in elektronische dossiersystemen.

\section{Discussie}

Normale groei van te vroeg geboren kinderen Onze resultaten laten zien dat matig te vroeg geboren worden, leidt tot een minder goede groei gedurende de eerste 4 levensjaren. Ongeveer $5 \%$ van de matig te vroeg geboren kinderen had een gewicht en/of lengte onder de -2 SDS. De groep kinderen met groeiachterstand bestond vooral uit kinderen die zijn geboren met een gewicht dat past bij de zwangerschapsduur (AGA) die niet zo goed groeiden, en enkele kinderen die bij de geboorte al te licht waren (SGA) en geen inhaalgroei lieten zien. In het eerste levensjaar hebben matig te vroeg geboren kinderen weliswaar enige inhaalgroei in de richting van op tijd geboren kinderen, maar deze is meestal beperkt van omvang.

We vonden geen significant verschil tussen de hoofdomtrek van matig te vroeg geboren kinderen aan het einde van het eerste levensjaar en die van op tijd geboren kinderen. De groei van de hoofdomtrek vlakt gewoonlijk tegen het eind van de zwangerschap af en wordt gevolgd door een toename in groeisnelheid in de eerste 6 levens- maanden. De hoofdomtrek van te vroeg geboren kinderen groeit in deze periode sneller dan die van op tijd geboren kinderen. Wat opvalt is dat de groei van de hoofdomtrek niet optreedt in de eerste levensweken, maar pas daarna. Een verklaring hiervoor ontbreekt. ${ }^{13,14}$ Er is meer onderzoek op dit gebied nodig.

\section{Voorspellers van groeiachterstand}

We vonden verschillende factoren die al ten tijde van de geboorte een minder goede groei voorspelden. Te licht zijn voor de zwangerschapsduur (SGA) had het sterkste verband met groeiachterstand op 4-jarige leeftijd wat terug te voeren is op het achterwege blijven van de inhaalgroei in deze specifieke subgroep, zoals we die kennen van de veel te vroeg geboren kinderen. 4,5 Voorspellers van groeiachterstand op de leeftijd van 4 jaar bij kinderen met een passend geboortegewicht voor de zwangerschapsduur (AGA) waren vergelijkbaar met die voor de totale groep matig te vroeg geboren kinderen. Vroeggeboorte op zich heeft dus grote invloed op de groei en de groeiachterstand is niet het gevolg van een laag geboortegewicht alleen.

Een kleine lengte van moeder is een bekende risicofactor voor onvoldoende lengtegroei in de normale populatie. ${ }^{11,15}$ Dit geldt ook voor matig te vroeg geboren kinderen. Het was verrassend dat we ook een verband vonden met minder goede gewichtstoename. Voor zover ons bekend is dat niet eerder gerapporteerd. De effecten van kleine moederlengte worden deels gecamoufleerd door de effecten van een te laag geboortegewicht voor de zwangerschapsduur. ${ }^{16}$ Dit geldt ook voor op tijd geboren kinderen. Omdat (voor zover bekend) een kleine moederlengte niet samenhangt met vroeggeboorte corrigeerden wij niet voor moederlengte.

Een laag opleidingsniveau bij moeder hield alleen verband met onvoldoende groei van de hoofdomtrek gedurende het eerste jaar. Een laag opleidingsniveau kan samenhangen met een kleine hoofdomtrek bij moeder, wat erop kan wijzen dat het verband dat we vonden een genetische oorsprong heeft. Wij hebben geen hoofdomtrek bij moeder gemeten, dus dit behoeft nadere bestudering. Vergelijkbare bevindingen zijn recentelijk ook bij andere studies gerapporteerd. ${ }^{12}$

We vonden geen andere factoren die van invloed waren op de groei. Factoren als een laag gezinsinkomen, de leeftijd van moeder en meerlingzwangerschap worden vaak in verband gebracht met vroeggeboorte, ${ }^{17}$ maar hebben blijkbaar geen invloed op de groei over een langere periode behalve via de zwangerschapsduur. Roken tijdens de zwangerschap leidt vaak tot een laag geboortegewicht, ${ }^{18}$ maar niet in dit onderzoek en het beïnvloedde ook de groei op de langere termijn niet. Ook andere factoren waarvan we verwachtten dat deze zouden leiden tot een tragere groei, zoals borstvoeding gedurende de eerste 6 maanden, geslacht en IVF of ICSI konden niet als voorspellers worden aangemerkt. Een 
Figuur 1 Voorbeeld van groeidiagram van o-4 jaar van jongens geboren na een zwangerschapsduur van 32 weken (32 weken en o dagen $\mathrm{t} / \mathrm{m}$ 32 weken en 6 dagen).
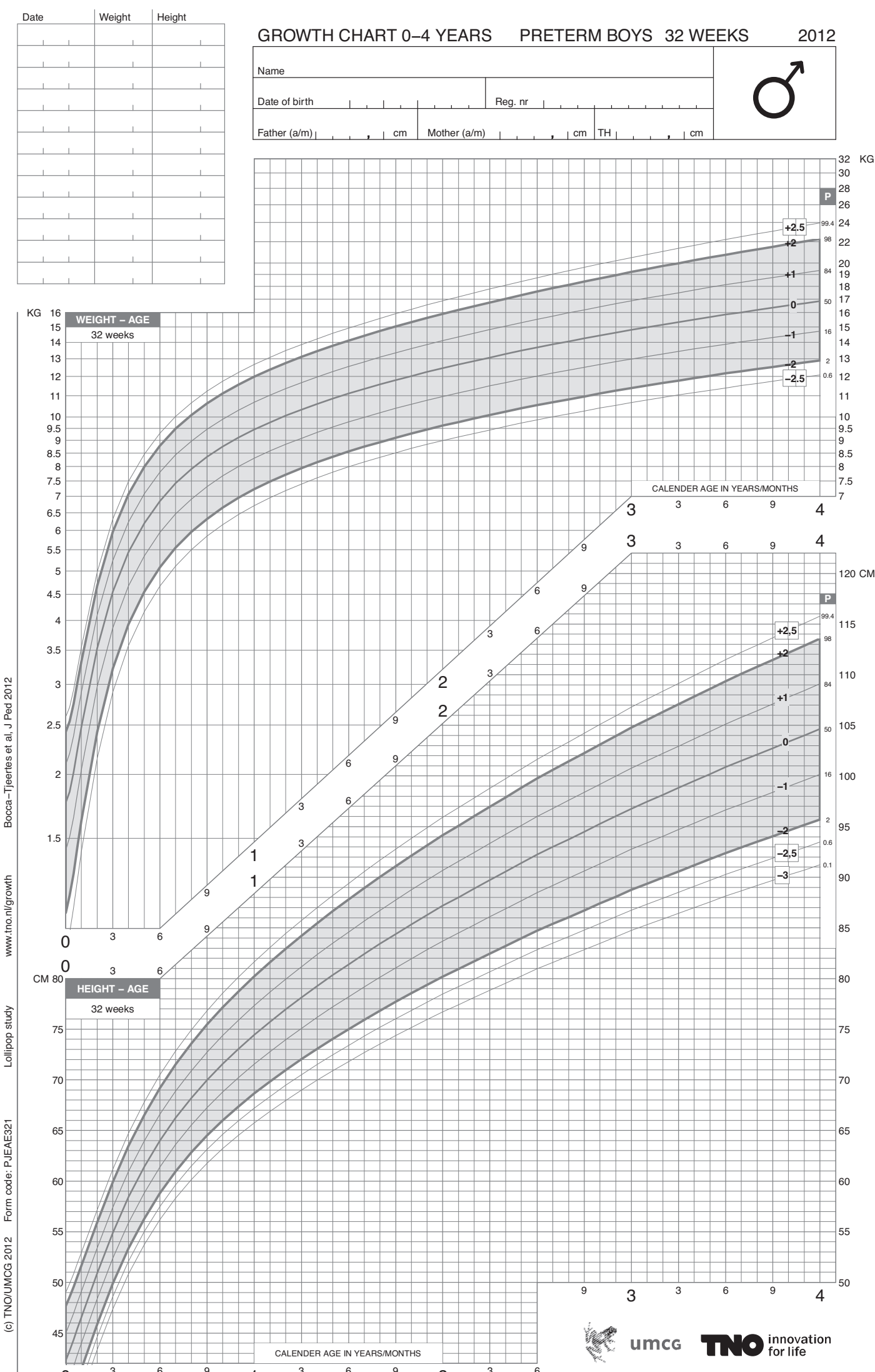
consistent gegeven bij onderzoeksgroepen van op tijd geboren kinderen is dat borstvoeding overgewicht op volwassen leeftijd voorkomt. ${ }^{19}$ Borstgevoede, te vroeg geboren kinderen in dit onderzoek wogen minder dan de flesgevoede kinderen op 4-jarige leeftijd, maar dit verschil was niet significant $(p=0,06)$. Het is onbekend of groei op de lange termijn bij matig te vroeg geboren kinderen door voedingsgewoonten wordt beïnvloed. Tenslotte leidde in ons onderzoek kunstmatige conceptie via IVF of ICSI niet tot minder goede groei, hoewel anderen het wel met minder hoog geboortegewicht in verband hebben gebracht. ${ }^{20}$

\section{Groeidiagrammen}

Dit onderzoek heeft goed bruikbare en nauwkeurige groeidiagrammen voor prematuren opgeleverd. De modellen die we daarvoor ontwikkelden, tonen aan dat vroeggeboorte leidt tot een lager gewicht en een kleinere lengte op de leeftijd van 4 jaar. Daarnaast vonden we zowel ten aanzien van gewicht en lengte, als ten aanzien van hoofdomtrek, bij jongens een grotere variabiliteit dan bij meisjes in de aan zwangerschapsduur gerelateerde groei. Mogelijk is deze bevinding een uiting van het feit dat te vroeg geboren jongens gevoeliger zijn dan meisjes voor complicaties van vroeggeboorte die groei beïnvloeden. Andere studies laten een hogere prevalentie zien van voorspellers van abnormale groei bij veel te vroeg geboren jongens. ${ }^{21}$ Een verklaring hiervoor zal door middel van aanvullend onderzoek gevonden moeten worden.

\section{Sterke en zwakke kanten}

De sterke punten van deze studie zijn de grote onderzoeksgroep, het feit dat de onderzoeksgroep vrijwel de hele range van te vroeg geboren kinderen omvatte en het gebruik van de combinatie van klinische gegevens en gegevens die afkomstig waren uit de jeugdgezondheidszorg. Verder onderzochten we de groei longitudinaal, wat zelden gebeurt.

Ons onderzoek heeft ook beperkingen. Ten eerste vonden we kleine verschillen in sociaal-economische status tussen de deelnemers en niet-deelnemers. Waarschijnlijk beïnvloeden deze verschillen onze uitkomsten nauwelijks, aangezien de sociaal-economische status de groei (gewicht en lengte) op de langere termijn niet lijkt te beïnvloeden. Ten tweede gebruikten we de Vierde landelijke groeistudie als referentie. Deze is gebaseerd op kinderen die kort na 1997 werden geboren, terwijl de kinderen uit ons onderzoek in 2002 en 2003 geboren zijn. Lengte en hoofdomtrek zijn niet toegenomen sinds 1997, maar het gewicht wel. Hierdoor kan er sprake zijn van onderschatting van groeiachterstand in gewicht bij de matig te vroeg geboren kinderen uit deze studie. Verder zijn retrospectief verzamelde gegevens over roken tijdens de zwangerschap mogelijk gevoelig voor bias, hoewel Jaspers et al. hebben aangetoond dat het geheugen van moeders over het rookgedrag tijdens de zwan- gerschap goed is, zelfs na 10 jaar follow-up..$^{22}$ Een andere beperking van dit onderzoek is dat het cohort voor meer dan $95 \%$ uit autochtone moeders bestond. Recent onderzoek suggereert echter dat de resulterende groeidiagrammen gegeneraliseerd kunnen worden naar andere populaties. $^{23}$

\section{Conclusie}

In deze grote longitudinale studie verschilde de groei van matig te vroeg geboren kinderen significant van die van op tijd geboren kinderen; ongeveer $5 \%$ van de matig te vroeg geboren kinderen had een gewicht en/of lengte van minder dan -2 SDS op 4-jarige leeftijd. De groei van de hoofdomtrek was op de lange termijn vergelijkbaar met die van op tijd geboren kinderen.

'Een kleine lengte van moeder' en 'een laag geboortegewicht voor de zwangerschapsduur' (SGA) voorspellen groeiachterstand op de leeftijd van 4 jaar. Een laag opleidingsniveau van moeder bleek in negatieve zin geassocieerd met de groei van de hoofdomtrek.

Voor de totale groep lagen tot de leeftijd van 4 jaar de mediane waarden voor lengte en gewicht onder die van op tijd geboren kinderen. Zowel gewicht als lengte als hoofdomtrek liet bij jongens grotere verschillen zien dan bij meisjes.

De ontwikkelde groeidiagrammen voor te vroeg geboren kinderen zijn een goed instrument om groei buiten de normale range op te sporen.

\section{Dankwoord}

Dit onderzoek werd mogelijk door financiële bijdragen van de Stichting Beatrix Kinderziekenhuis Onderzoeksfoundation, de Cornelia-Stichting, het A. Bulk Stimuleringsfonds en De Nederlandse Hersenstichting en heeft een onderzoekssubsidie zonder voorwaarden ontvangen van Friesland Campina (Friso kindervoeding) en Pfizer Europe. De financiers hadden in geen enkel stadium een rol in de vormgeving of de rapportage over het onderzoek. Het onderzoek was niet mogelijk geweest zonder de inzet van vele consultatiebureaumedewerkers. Speciale dank gaat uit naar M. Broer van Dijk en B. van der Hulst voor hun coördinerende rol bij de dataverzameling.

\section{Literatuur}

1. Perinatal Care in the Netherlands 2006 (in Dutch). Utrecht: Stichting Perinatale Registratie Nederland; 2008.

2. Hack M, Schluchter M, Cartar L, Rahman M, Cuttler L, Borawski E. Growth of very low birth weight infants to age 20 years. Pediatrics. 2003;112(1):e30-8.

3. Ford GW, Doyle LW, Davis NM, Callanan C. Very low birth weight and growth into adolescence. Arch Pediatr Adolesc Med. 2000;154(8):778-84.

4. Cooke RJ, Ainsworth SB, Fenton AC. Postnatal growth retardation: a universal problem in preterm infants. Arch Dis Child Fetal Neonatal Ed. 2004;89(5):F428-30. 
5. Wood NS, Costeloe K, Gibson AT, Hennessy EM, Marlow N, Wilkinson AR. The EPICure study: growth and associated problems in children born at 25 weeks of gestational age or less. Arch Dis Child Fetal Neonatal Ed. 2003;88(6):F492-500.

6. Guo SS, Roche AF, Chumlea WC, Casey PH, Moore WM. Growth in weight, recumbent length, and head circumference for preterm low-birthweight infants during the first three years of life using gestation-adjusted ages. Early Hum Dev. 1997;47(3):305-25

7. Kloosterman G. On intrauterine growth, the significance of prenatal care. Int J Gynaecol Ostetr. 1970;8:895-912.

8. Bocca-Tjeertes IF, Kerstjens JM, Reijneveld SA, Winter AF de, Bos AF. Growth and predictors of growth restraint in moderately preterm-born children aged o-4 years. Pediatrics. 2011 Nov;128(5):e1187-94

9. Bocca-Tjeertes IF, Buuren S van, Bos AF, Kerstjens JM, Vergert EMJ ten, Reijneveld SA. Longitudinal growth charts for preterm born children GA 25-36 weeks: integrating median growth and variability. J Pediatr. 2012;161:460-5.

10. Vergert L ten, Kerstjens J, Bocca-Tjeertes I, Buuren S van, Winter A de, Reijneveld M, e.a. De ASQ en de ontwikkeling van matig te vroeg geboren kinderen, resultaten van het Pinkeltje Onderzoek. Tijdschr JGZ. 2012(44)3:42-9.

11. Giacobbi V, Trivin C, Lawson-Body E, Fonseca M, Souberbielle JC, Brauner R. Extremely short stature: influence of each parent's height on clinical-biological features. Horm Res. 2003;6o(6):272-6.

12. Silva LM, Jansen PW, Steegers EA, Jaddoe VWVK, Arends LR, Tiemeier H, e.a. Mother's educational level and fetal growth: the genesis of health inequalities. Int J Epidemiol. 2010;39(5):1250-61.

13. Cockerill J, Uthaya S, Dore CJ, Modi N. Accelerated postnatal head growth follows preterm birth. Arch Dis Child Fetal Neonatal Ed. 2006;91(3):F184-7.
14. Latal-Hajnal B, Siebenthal K von, Kovari H, Bucher HU, Largo RH. Postnatal growth in VLBW infants: Significant association with neurodevelopmental outcome. J Pediatr. 2003;143(2):16370.

15. Luo ZC, Albertsson-Wikland K, Karlberg J. Target height as predicted by parental heights in a population-based study. Pediatr Res. 1998;44:563-71.

16. Zhang X, Mumford SL, Cnattingius S, Schisterman EF, Kramer MS. Reduced birth weight in short or primiparous mothers: physiological or pathological? BJOG. 2010;117:1248-54.

17. Goldenberg RL, Culhane JF, Iams JD, Romero R. Epidemiology and causes of preterm birth. Lancet. 2008;371(9606):75-84.

18. Lanting CI, Buitendijk SE, Crone MR, Segaar D, Bennebroek Gravenhorst J, Wouwe JP van. Clustering of socioeconomic, behavioral and neonatal risk factors for infant health in pregnant smokers. PLoS One. 2009;4(12):E8363.

19. Shields L, Mamun AA, O'Callaghan M, Williams GM, Najman JM. Breastfeeding and obesity at 21 years: a cohort study. J Clin Nurs. 2010;19(11-12):1612-7.

20. Pelinck MJ, Keizer MH, Hoek A, Simons AH, Schelling K, Middelburg K, e.a. Perinatal outcome in singletons after modified natural cycle IVF and standard IVF with ovarian stimulation. Eur J Obstet Gynecol Reprod Biol. 2010;148(1):5661.

21. Klein K, Worda C, Stammler-Safar M, Husslein P, Gleicher N, Weghofer A. Does fetal sex influence the risk of preterm delivery in dichorionic twin pregnancies after spontaneous conception? Twin Res Hum Genet. 2010;13(5):495-500.

22. Jaspers M, Meer G de, Verhulst FC, Ormel J, Reijneveld SA. Limited validity of parental recall on pregnancy, birth, and early childhood at child age 10 years. J Clin Epidemiol. 2010;63(2):185-91.

23. Rao SC, Tompkins J, WHO. Growth curves for preterm infants. Early Hum Dev. 2007;83(10):643-51. 